\title{
Nuevos soportes y formatos: los cambios editoriales en el campo de la historieta argentina
}

\author{
LAURA CRISTINA FERNÁNDEZ Y SEBASTIAN HORACIO GAGO \\ UNIVERSIDAD NACIONAL DE CÓRDOBA (ARGENTINA)-CONICET
}

ABSTRACT: This paper tackles some recent transformations in the edition, circulation and consumption of comics in Argentina. We offer a theoretical perspective to examine the changes in the comic book production beyond a national editorial field in particular. For this purpose, we will analyze the changes in format and layout of these cultural products, as well as the transformation of their mechanisms and agents with regard to this particular area. We will also take into account the trends pointing towards the changes in the instances of legitimization of their authors and products, which can be understood as a consequence of literary, economic and political pressures. We have discovered an overlap of these social spaces with those of the comic field, because of its having certain regions more autonomous than others (Bourdieu, 1995). We have observed that, in the last two decades, the book has become the main edition cradle for comics, parallel to the emergence of libraries and comic stores as the prevailing places for their circulation. This paper also studies the role of new technologies and New Media (Igarza, 2008) in the circulation and consumption of comics, as well as some instances of the canonization of works and authors.

Keywords: layouts, edition, comic books, consumption, technology.

RESUMEN: En este trabajo nos proponemos abordar algunas de las transformaciones sufridas en el campo de la edición, la circulación y el consumo de historietas en Argentina. Nos proponemos presentar una perspectiva teórica que permita, más allá de un mercado o campo editorial de un país en particular, observar las transformaciones producidas en las últimas tres décadas en la producción de un tipo de bien cultural: las historietas. Nos detendremos a analizar la mudanza de los formatos y los soportes de estos productos culturales y, correlativamente a ello, la transformación de los criterios, mecanismos y agentes de consagración del campo de las historietas. Al respecto, tendremos en cuenta las tendencias hacia la heteronomía del campo en relación con las instancias de legitimación de sus productores y sus productos, situación que puede entenderse a la luz de las presiones provenientes del campo económico o empresarial capitalista, del campo del arte literario y del campo estatal-gubernamental. Desde nuestra perspectiva observamos un solapamiento de estos espacios del universo social con el campo de 
la historieta, entendiendo a éste último como un espacio del campo cultural que cuenta con ciertas regiones más autónomas y otras más heterónomas respecto de espacios y capitales (Bourdieu, 1995) externos al mismo. Una de las tendencias cuya explicación desarrollaremos en nuestro trabajo es aquella por la cual, en las últimas dos décadas, el libro ha pasado a ser el soporte privilegiado en la edición de historietas, conjuntamente a la aparición de librerías -lugar de cultura "distinguida" o "culta"- y las comiquerías o tiendas especializadas en venta de historietas y merchandising relacionado a las mismas, como lugares predominantes en la circulación. Asimismo, indagaremos el papel clave que juegan los nuevas tecnologías y nuevos medios de comunicación digitales (Igarza, 2008) en la circulación, consumo y las instancias de consagración de obras y autores.

Palabras clave: formatos, edición, historietas, consumo, tecnologías.

\section{Desarrollo}

El presente artículo intentará indagar sobre las modificaciones, relecturas y desplazamientos suscitados en el campo/mercado de la historieta argentina con la incursión de los nuevos formatos de edición (weblogs y novelas gráficas). Para ello, describiremos algunas características del campo en cuestión para poder delinear el impacto/las condiciones de emergencia de los nuevos formatos del mercado.

Nuestra perspectiva teórico-metodológica abreva en la sociología de la cultura de Pierre Bourdieu, los estudios culturales británicos, la historia de la lectura de Roger Chartier y teorías de consumos culturales de autores latinoamericanos como Martín-Barbero y Roberto Igarza.

La utilidad de esta descripción introductoria del marco contextual es reconstruir ciertas circunstancias socio-históricas que han rodeado a nuestro objeto de estudio, circunstancias que consideramos pertinentes para comprenderlo, como son las condiciones de producción, las prácticas de recepción y consumos de historietas. Dar cuenta de esos factores contextuales (Morley, 1996) permite reconstruir tanto los sentidos producidos y puestos en circulación en estas prácticas, como los discursos construidos sobre las mismas.

Emplearemos la teoría de Jesús Martín-Barbero para definir las nociones de consumo y lectura o recepción. El consumo es entendido por este autor-quien recupera y reformula la concepción marxista del mismo- (Martín-Barbero, 1987: 231 y ss.) como:

[...] el conjunto de procesos sociales de apropiación de los productos [...] no es solo reproducción de fuerzas, sino también producción de sentidos: lugar de una lucha que no se agota en la producción de objetos, pues pasa aún más decisivamente por los usos que les dan forma social y en los que se inscriben demandas y dispositivos de acción que provienen de diferentes competencias culturales. 
La recepción o lectura, por otra parte, es «la actividad por medio de la cual los significados se organizan en un sentido», donde no hay solo reproducción, sino también producción de sentido (Ibíd.). Por sentido entendemos los modelos de/sobre la realidad que se construyen y ponen en circulación en los distintos tipos de discursos (Bourdieu, 1995; Verón, 1993).

Respecto de las prácticas de recepción, la noción de illusio (Bourdieu, 1995) es el deseo que impulsa a los agentes de un determinado campo de la vida social a participar en el mismo y jugar el juego. Esta illusio, es la creencia en el valor del juego y el interés en el juego, que varía según los participantes y la posición que ocupan como así también según su trayectoria recorrida en el campo. La illusio es lo que inclina a los agentes y los dispone a efectuar las distinciones pertinentes desde el punto de vista de la lógica del campo; a distinguir lo que es importante de lo que no (Bourdieu, 1995: 253, 260 y 337), y se expresa en los intereses, prácticas y relaciones de los agentes que consumen historietas tejen respecto de los otros agentes y capitales que se mueven en el campo, ya sean otros consumidores, críticos, autores, medios de comunicación, publicaciones u obras.

En la Argentina, desde principios del siglo xx hasta comienzos de los años noventa, el campo editorial de la historieta -así como todo el campo de la edición literaria-funcionó dentro de la lógica de la industria cultural a la que se correspondía un espacio de consumo masivo. El formato predominante del producto eran las revistas de historietas publicadas por entrega o continuadas. Sin embargo, en los noventa desapareció la publicación de historietas como actividad de la industria editorial, principalmente debido a la desocupación laboral y a una drástica reducción de los ingresos en las clases medias y populares, lo cual generó una fuerte desigualdad social. En este nuevo contexto desapareció en su mayoría el lector de clases obreras y populares, en tanto el consumo de historietas se limitó a grupos reducidos de lectores. La composición empresarial de la industria argentina de historietas consistía en dos editoriales grandes (Columba y Record) y muy poco más, lo que aumentaba su fragilidad. La crisis en el campo de producción local, sumado a la importación de revistas extranjeras (favorecida por la paridad cambiaria) provocó una modificación en los gustos y consumos, asimismo desplazamientos en las formas de producción y circulación de la historieta: por un lado, los consagrados artistas locales se orientaron a la realización para el extranjero; por otra parte, los guionistas y dibujantes emergentes encontraron en el fanzine un formato de subsistencia, intersticial en un mercado editorial restringido, para poder difundir su trabajo. La autoedición será, pues, un tipo de producción que responderá en menor medida a los mandatos del mercado. «La práctica de la autoedición (característica constitutiva de un fanzine) responde según Williams a un tipo de producción tentativa de alternatividad que representa por lo menos una iniciativa de diferenciación respecto a las relaciones de producción dominante» (Vazquez, 2002).

De la «movida» de fanzines de los años noventa, surgieron obras (Cazador, Morón Suburbio, y las revistas Catzole, El tripero, Lápiz Japonés yiSuélteme!) 
y artistas que han participado en la producción de historietas on-line, y han alcanzado reconocimiento a partir del nuevo milenio. Un caso es la editorial cordobesa Llanto de Mudo, que Diego Cortés, Pablo Peisino y Federico Rübenacker fundaron a mediados de los noventa: «Como jóvenes punks a los que les gustaba la historieta, la poesía, la pintura, la música y no compartían la forma en que los otros realizaban algunas de estas cosas, no nos pusimos a quejarnos sino simplemente creamos nuestra forma de editar y comunicarnos con los demás» (Cortés, citado por Valenzuela, 30 de enero de 2011).

\section{Cambios en la circulación}

Mientras la circulación de las historietas se ha restringido y ralentizado, ha existido, a la vez, un cambio en la valorización de estos productos. Actualmente, las revistas o libros de historietas en general no se canjean, ${ }^{1}$ son coleccionados por el lector, y en algunos casos integran su biblioteca particular junto a otros títulos literarios. Este fenómeno de apropiación, tanto material como simbólica, que modifica el proceso de circulación y consumo mismo, está vinculado a los cambios en la materialidad del producto, cuya producción es más limitada que en el periodo anterior: la historieta argentina ha pasado a ocupar un subcampo de producción cultural que denominamos «arte por el arte»o «producción para productores» (Bourdieu, 1995). Una obra con formato e impresión lujosa (libro de tapa dura, papel de alta calidad) condiciona la circulación que se va a operar de ese bien cultural. Al respecto, la revista Fierro, en la primera etapa de su trayectoria (1984-1992), ha sido clave en los cambios en la circulación y el consumo: en ella, «la historieta adquiere un valor estético inalienable. Se trata de la primera revista de historietas que es, incuestionablemente, una revista de colección [...]: es el objeto de un gesto de conservación, de una estrategia de acumulación -hace falta "tener la Fierro"» (Berone, 2009: 4).

Hace una década, cuando la industria editorial de historietas comienza a recuperarse de la debacle de los noventas y de la crisis de 2001-2002, aparecen pequeñas y medianas empresas basadas en la publicación en papel de lo publicado inicialmente en Internet.

En este sentido, las publicaciones en Internet pasan a ser referentes de los lectores y de los productores, pues constituyen un filtro previo a la circulación del producto en material impreso. Surgidos con un fin muy similar al del fanzine, los

1. Establecemos como hipótesis que en la actualidad, el canje de historietas realistas en la ciudad de Córdoba se limita preferentemente al dos por uno practicado en algunas librerías de saldos y usados, que tienen como objeto de trueque a las viejas revistas de Editorial Columba, como El Tony, D’Artagnan y Fantasía. 
blog de historietas se constituyen como espacios de transmisión del trabajo de los nuevos autores, a modo de propuestas recopilatorias on-line y como espacio de vínculo social e intercambio y debate con el público (Caraballo, 2010: 4).

Como «pensar una historieta sin considerar sus condiciones de publicación es un despropósito» (Reggiani: 2009), es necesario tener en cuenta al weblog como herramienta de difusión, publicación e intercambio. Diferenciándose del fanzine, cuyas tiradas son pequeñas y artesanales, el blog se constituye como un medio masivo que puede alcanzar audiencias insospechadas (Caraballo, 2010). Igarza (2008: 211-212) marca esa diferencia de acceso, entre los medios masivos y los NM:

\begin{abstract}
El blogging puede ser un fenómeno limitado y no algo masivo, como son los medios tradicionales. [...] En la sociedad industrial, la producción de contenidos estaba estrechamente ligada a la capacidad de difusión. Comunicar masivamente o en grandes volúmenes requería a las editoriales capacidades técnicas, logísticas y económicas importantes para hacer llegar el contenido hasta los destinatarios del mensaje. Estas disposiciones no eran accesibles para cualquier ciudadano, sino reservadas en exclusividad a las industrias de contenidos. La comunicación era unívoca. Al inicio, el modelo digital no presentó diferencias con el modelo anterior ya que ofrecía tantas dificultades técnicas para la edición y publicación de contenidos, que el mandato social anterior se prolongó sin mayores cuestionamientos debido a que las barreras a las que debía enfrentarse el autor a la hora de publicar sus opiniones en Internet resultaban prácticamente infranqueables. Pero los blogs hicieron que la tarea fuese mucho más simple.
\end{abstract}

\title{
3. Recepción y difusores culturales
}

Vinculado a los reacomodamientos en la producción y en los consumos, pensamos que una de las fuentes de conocimiento del lector son los difusores culturales. Cumplen la función de recomendar, marcar o informar sobre determinados productos culturales ante consumidores o potenciales consumidores, contribuyendo en el proceso de marcación del producto por parte de los mismos lectores. Los difusores median entre la producción y el consumo, ocupando una posición significativa y generando efectos en el campo de circulación de la mercancía cultural: ofician como banqueros simbólicos, al transmitir o transferir parte de su capital conocimiento a lectores más o menos avezados en el código de recepción. Asimismo, determinados bienes culturales -y sus productores- pueden adquirir o revalorizar su crédito simbólico en virtud del trabajo de los difusores. Lo que es parte de una labor colectiva y estratégica de construcción de la creencia en el juego del arte, en el valor de la historieta, en el poder creador del autor y en el poder cultural de ciertos tipos de difusores (especialistas, críticos, divulgadores, dueños de comiquerías, etc.). La illusio implica una especie de disposición militante a asistir 
casi religiosamente a charlas, exposiciones y festivales de historietas (Vazquez, 2011: 32), a tener contacto o interactuar con agentes difusores o a participar en espacios como los weblogs dedicados a la publicación y a la crítica.

Algunos de estos factores en juego en el campo actual pueden observarse en las opiniones de Andrés Accorsi, reconocido crítico y distribuidor de historietas en Cuadritos (17 de mayo de 2009). Respecto a su labor de quince años con la revista Comiqueando, Accorsi señala un sentido de pertenencia a una «comunidad comiquera»: «Nos abrió muchas puertas, nos dio amigos, laburos, viajes y un reconocimiento muy lindo de los historietistas, que son los tipos que nos hicieron fans de esto» (Valenzuela, 2009). Asimismo destaca cierto rol legitimador de su revista al dar visibilidad a historietistas muy jóvenes y desconocidos que luego adquirieron renombre. También destaca cómo la crisis del 2001-2002 afectó a las publicaciones: «Pensé que de ahí no volvíamos [...] pero se volvió, a mí me sorprende esa capacidad de regeneración que tiene el país en general y el mundillo de la historieta en particular» (Valenzuela, 2009).

La posesión y acumulación de capital social, la red de relaciones que el agente construye en diferentes espacios, permite el contacto con difusores e instancias de mediación, lo que reproduce el capital social como medio de apropiación cultural. Los difusores culturales pueden ser amigos, familiares, compañeros de escuela, productores de bienes culturales, instituciones educativas o de formación de productores culturales, publicaciones especializadas, el Estado, curadores de eventos, académicos, blogs especializados, periodistas, críticos, medios de comunicación, editores, dueños de comiquerías, ${ }^{2}$ etc. Estas últimas ocupan una posición y rol gravitante dentro del campo de circulación de las historietas impresas, que incluye otros puntos de salida de productos: librerías, locales de usados, saldos, kioscos, exposiciones, y eventos sobre historietas.

\section{Nuevos medios y nuevos formatos}

Dentro de las condiciones de producción socio-culturales, deberemos incluir, por un lado, la indagación de los modos de selección y de utilización (Mata, 1997: 8) de las historietas en sus diferentes formatos y soportes -tanto impresos como digitales- $y$, por otra parte, el sentido que los individuos invisten a estos

2. «Las comiquerías son "tiendas de cómics", pero también tienda de juegos de rol, de remeras temáticas, de libros y videos relacionados con la ciencia ficción, con el cine masivo, y también ofrecen el merchandising que Hollywood lanza junto con sus películas. [Su éxito] estuvo dado por [...] la apertura a las importaciones, aprovechando el nuevo auge en el mercado global del comic book norteamericano y del manga y el animé japonés, relacionados también con la rápida expansión en los noventa de la televisión por cable» (von Sprecher y Williams, 2008: 4-5). 
consumos y que, a su vez, estos consumos ponen en circulación en la red comunicacional micro, meso y/o macrosocial (von Sprecher, 2006).

La recepción de historietas on-line se da en un espacio que promueve el vínculo social y el intercambio y debate con el público (Caraballo, 2010: 4), proceso aún en desarrollo que ha implicado cambios en torno al estatus del lector, quien pasa a ser productor de sentido ya no solo en recepción sino también incidiendo en muchos casos en la producción de historietas. Si bien ambos pueden considerarse formas de circulación y visibilidad de historietistas jóvenes $-\mathrm{y}$, a la vez, espacios que llevan a actualizar o renovar los agentes en pugna del rol de referente y/o productor- algunas diferencias entre el formato fanzine y la historieta on-line son señaladas por Diego Cortés: «Yo empecé en el noventa y pico a sacar libritos. Y tiene que haber sido como en el dos mil que empezamos a tener mail como para comunicarnos. Antes era todo por correo, me llegaban cartas a mi casa, todo. Yo nunca tuve un blog bien armado, digamos» (Gago y Fernández, 2012, documento interno de trabajo inédito). Este editor y guionista observa que el blog funciona como portfolio de los artistas y que, al ser cada vez más accesible y no precisar de un capital inicial para editarse, ha reducido el espacio del fanzine. Asimismo, este formato generó cambios en los fanzines, simbólicos (la valoración de la materialidad, del tipo de papel) y estéticos (mayor calidad en la impresión, uso del color):

Yo ya saqué tanta revista barata y tantos fanzines que me cansé, dije «bueno o mejoramos o chau». Los pibes que hacen fanzines están medio delirados también con la calidad del laburo, ya piensan en color y todo, y yo cuando empecé era fotocopia, y te da una forma de laburar... te hace mejorar laburando, que es distinto a esto de laburar y estar haciendo cosas solo y no mostrándolas tanto. Hay blogs que se leen mucho ¿no? Pero me parece que uno no lee una historieta larga en un blog [...] a la vez, le sirve al autor para estar obligado a hacer algo toda la semana [...] Si no habría mucha gente que no haría nada. Todos esos libros [...] todas esas historietas en blog están deviniendo en libro.

Esta última frase de Cortés nos introduce en otro formato, la novela gráfica, que no es nuevo en el campo pero que ha renovado un debate concerniente a la tensa relación entre consumo masivo y consumo intelectual/artístico. Uno de los factores contextuales que condiciona la relación de los lectores con las historietas es la posición que ocupa esta forma narrativa en el subcampo de géneros narrativos masivos, dentro del espacio cultural de una sociedad, lo cual puede afectar a la percepción que de la historieta se hagan los individuos consumidores. Por ejemplo, la calificación -y clasificación- de la historieta como «novela gráfica» es otro caso de revalorización plasmado en lo nominal, que se relaciona con el proceso de ganancia de cierta autonomía artística en que entra el campo a partir de los años noventa.

Max Aguirre, en un panel sobre historieta y novela gráfica en la librería Eterna Cadencia (Buenos Aires, marzo de 2011) señala algunas tensiones que suscita 
esta (parcial) legitimación artística de la historieta en los formatos y en las prácticas del campo:

El tema es que además la historieta no ofrece, en líneas generales (recién ahora, un poco) cierto capital simbólico. Es muy difícil lograr un espacio en algún suplemento cultural para poder mostrar o hablar de historieta. Eso está hablando de cuál es el lugar que ocupa dentro de la cultura actual la historieta, si bien ocupa un lugar más destacado que antes. Además, creo que la historieta está atravesando un cambio de campo: de ser un arte aplicado o un oficio artístico, que empleaba a un montón de gente y que ocupaba un lugar determinado en la cultura popular, está empezando a transformarse, a ocupar campos que son de la cultura, de la cultura de siempre. Empieza a tener que aprender a lidiar con determinadas reglas que no eran con las que lidiaba antes.

En el marco de esa misma charla, tanto Aguirre como Federico Reggiani admiten que existe un mayor reconocimiento de la historieta, aunque son más cautos respecto a un supuesto «boom»y, por su parte, Martín Ramón (editor de Moebius) tiene una postura más optimista, no solo debido a la mayor cantidad de publicaciones, sino también por el crecimiento de eventos sobre historieta como Viñetas Sueltas en Buenos Aires o Crack, Bang, Boom en Rosario.

La etiqueta «novela gráfica» ha sido creada y reproducida para realzar a las historietas ante ciertas instituciones culturales poseedoras de legitimidad y valoración social -editoriales, medios de comunicación-(Reggiani, 2011), aunque la historieta sigue teniendo un papel subordinado, considerándosela desde el campo literario «como un episodio de la cultura (y de la cultura del pasado) más que como un lenguaje artístico vivo» (Reggiani, 2009). Librada de la lógica productiva de la industria cultural, en este nuevo contexto se intenta elevar a la historieta al nivel de novela, género literario que históricamente ha sido dotado de un mayor prestigio y consagración cultural que las historietas. ${ }^{3}$ Contribuye a este etiquetamiento del producto el actual formato dominante de edición -y dentro de esta, la compilación y reedición de historietas originalmente publicadas en serie continuada-, que es el libro. Federico Reggiani (2010) considera al respecto:

[...] ahora empieza a mirar la historieta el mundo hipercodificado de la alta cultura. Estamos entre Escila y Caribdis: cuando no te agarra del cuello la mano invisible del mercado, te marcan la cancha las reglas del arte [...] Basta que una historieta se edite como un libro (¿y cuántas otras opciones nos quedan?) para que se novelice. No sorprende entonces que los historietistas empiecen a tener como destino y modelo un libro y, en tanto libro, una novela. Una de las muchas anomalías de

3. No obstante, algunos teóricos y críticos han definido la novela gráfica como «adaptaciones de obras literarias abordadas desde el lenguaje de la historieta». 
El Eternauta es ese temprano destino de libro, esa voluntad de novela que habilitó su rara canonización. No nos olvidemos de que una historieta que también es una novela es más fácil de editar y de reeditar.

Asimismo, el formato libro funciona como instancia de consagración de las historietas publicadas en blogs. Es el caso de Los resortes simbólicos, historieta que Aguirre publicó en el blog llamado Historietas Reales y que luego editó en formato libro. Al respecto, el historietista decía que «A Historietas Reales llegamos todos con un grado de maduración distinto como historietistas y a todos nos transformó» (Valenzuela, 2010); transformación que supuso la adquisición de espacios reconocidos de publicación como el diario La Nación y la revista Billiken. Respecto al blog, Aguirre agrega (Valenzuela, 2010):

El formato funcionaba muy bien con historieta autobiográfica y autoconclusiva [...] Teníamos la lógica de una programación televisiva [...] Eso en algún momento y por decisión conjunta se cambió en pos de publicar otras cosas. Porque en realidad Historietas Reales es una manera bastante funcional a los autores para generar obra: hay un montón de libros que han salido de ahí. Cuando empezó era parte de todo ese resurgir de la historieta argentina y era una de las pocas nuevas opciones [...] La ausencia de la novedad genera ciertos movimientos, pero no creo que se pueda decir que decayó. Sucedió el tiempo y si lo comparo con cualquier proyecto editorial, te diría que en eso somos sumamente clásicos [...] Sucedía en esa primera etapa que los comentaristas entraban a decir cosas porque las entregas eran acotadas y estaban copados con un espacio que antes no existía [...] Creo que hoy no ha bajado la cantidad de lectores, sino que cambió la dinámica. La maduración también conlleva ciertas instancias más aplacadas.

El blog permite un amplio intercambio con el público/espectador/lector de los nuevos medios, que en algunos casos son lectores de historietas impresas en papel. «Este feedback constante inaugura una nueva dimensión de simultaneidad en el consumo historietístico incluso modificando sobre la marcha los propios contenidos y mensajes» (Caraballo, Ob. cit.: 5). Esta idea se conecta con nuestra concepción de la comunicación como un lugar de negociaciones y de luchas abiertas o encubiertas entre agentes sociales con intereses diversos (von Sprecher, 2006), donde la construcción de sentido funciona tanto en la producción como en la recepción, y la correspondencia entre estas dos dimensiones nunca es exacta, siempre existe algún grado de asimetría de sentido, variable según los contextos mismos de producción.

Pese a esa capacidad de los blogs de historietas, de permitir el acceso de contenidos y mensajes a un público masivo, se trata de un público fragmentado, pues el uso de Internet impone barreras de accesibilidad: se deben contar con recursos económicos y culturales para la misma. La posibilidad de apropiación simbólica del bien cultural no depende ya de la compra, préstamo de la revista o 
libro impreso, sino de la posesión de saberes específicos y del acceso económico a Internet. El nuevo medio también propone lecturas con una lógica itinerante/ nomádica con reenvíos permanentes (Reguillo, 2000), que no es la misma que la lógica predominantemente lineal del mundo analógico (aunque cabe señalar que la lectura de historietas no es ni ha sido una práctica homogénea en todo lugar físico o espacio social, y los lectores no comparten los mismos gustos por los mismos tipos de productos). Dentro de esta lógica de acceso, consumo y participación activa de los usuarios en la producción de contenidos, se puede evaluar el producto sin tener que comprarlo y acceder a información y bienes específicos del campo que antes no eran posibles, en una diversificación de las posibilidades de elección de consumo. En este contexto, el lector de historietas suele constituirse en buena medida en un tipo de «comunidades de interpretación» (Chartier, 2002), en tanto el consumo de historietas, a partir de los noventas se redujo en términos de cantidad de lectores pese a la segmentación y la diferenciación actual de públicos. Los nuevos medios promueven otro tipo de masividad, en la que los mensajes no son recibidos de forma simultánea ni uniforme.

No podemos dejar de tener en cuenta, al hablar de la circulación de este producto cultural, las diversas instancias de consagración y legitimación de los productos historietísticos y sus autores, como los prólogos de libros, las críticas en el periodismo cultural y el espacio de crítica específica del campo de la historieta, las curaciones y presentaciones de obras, los eventos culturales. Tan sólo haciendo mención a El Eternauta, hoy encontramos una validación proveniente tanto del Estado como de muchas otras manifestaciones relacionadas con la industria cultural, como puede ser una película cinematográfica referida a esta historieta, un mural alusivo a ella en una estación de metro, una obra teatral inspirada en su argumento, el lanzamiento de un disco de música en su homenaje o hasta una línea de zapatillas de marca nacional cuyos productos llevan impresos motivos propios de la iconografía de esta historieta. Todo el campo de producción y ciertos espacios del campo de la cultura y del espacio social general exceden los límites del campo específico en una inmensa empresa de alquimia simbólica a la que contribuyen el conjunto de los agentes implicados en él, creando el valor de consagración de la obra historietística y la creencia en el poder creador del productor cultural (Bourdieu, 1995: 253 y ss.), la illusio que es condición de funcionamiento del campo.

En este sentido, ciertos habitus o disposiciones culturales, como el gusto por la lectura y por determinado tipo de historietas, constituyen un tipo de capital cultural en estado incorporado que, junto a sus agentes portadores, solo puede asegurar su perpetuación al precio de un proceso de socialización y, en ciertos casos, un trabajo de inculcación o aculturación (incorporación de estructuras ob- 
jetivas en estructuras subjetivas) que requiere una inversión desinteresada ${ }^{4}$ de tiempo (Bourdieu, 1988) que suele comenzar en la socialización familiar temprana. Es decir, la propensión a determinados consumos y a determinados modos de uso y apropiación de un bien cultural -que incluye los criterios clasificatorios, modos de ver, percibir y decir que disponen al agente para producir prácticas enclasables-, se relaciona con el volumen del capital cultural de una persona pero también con la estructura del mismo -las proporciones entre sus distintas especies- constituida a lo largo de su trayectoria. Por apropiación entendemos una práctica que para ejercerla se requiere una propensión y una aptitud, un gusto (Bourdieu, 1988: 172-173):

El gusto, propensión y aptitud para la apropiación (material y/o simbólica) de una clase determinada de objetos o de prácticas enclasadas y enclasantes, es la fórmula generadora que se encuentra en la base del estilo de vida, conjunto unitario de preferencias distintivas que expresan, en la lógica específica de cada uno de los subespacios simbólicos [...] la misma intención expresiva.

Notamos, al respecto, que la mayoría de los lectores de historietas, al menos los que ejercen esta práctica cultural desde el cambio de siglo en adelante, son significativamente equilibrados en sus consumos (lo cual tiene que ver con que la mayoría de los lectores son de clase media): ya no solo leen historietas (ya casi al final de este artículo, es dable aclarar que preferimos el término historietas para definir a nuestro objeto de estudio, siendo conscientes de la existencia de otras formas de nominar a estos productos culturales que son sinonímicas, como tebeo en España o cómic en Estados Unidos y extendida en Hispanoamérica en las últimas décadas), sino que también tienen fuerte disposición para la literatura o el cine, entre otros consumos culturales. Sobre este punto, Diego Cortés señala que «el lector de historietas [...] ahora está más equilibrado [...] antes leía historietas solas, es muy raro que leyera libros. Libros es más raro por ahí de leer en sí, pero

4. El desinterés o, más rigurosamente, el interés por el desinterés, es una especie de interés actuante, aunque no exclusivamente, en los campos culturales, ya sea en los campos de producción de bienes como en los espacios de producción social de los gustos. En los mismos se realizan prácticas que implican inversiones desinteresadas, que suponen un interés propio de un mundo donde la economía y el interés económico están negados (Bourdieu, 1988: 247). Es el interés por la acumulación de una especie de capital específico de los campos de producción y consumo de bienes simbólicos, que solo se podrá traducir en beneficios económicos o sociales de manera diferida en el tiempo, a largo plazo. En estos universos, se constituye así una economía al revés (Bourdieu, 1995: 128 y ss.), toda una serie de mecanismos, estrategias y prácticas que tienen en común la disimulación del juego del interés y del cálculo económico y las relaciones económicas. Rige una lógica que sitúa al prestigio, al reconocimiento, en definitiva al capital simbólico-estético, como carta de negociación y de poder de fijación de los precios de los productos, de los productores y de los demás agentes del campo. 
ahora sus intereses son más amplios» (Gago y Fernández, documento de trabajo inédito).

\section{Consideraciones finales}

El campo de la historieta experimenta una paulatina y creciente autonomización, principalmente observable en la introducción de nuevas formas de narrar, en el reconocimiento del historietista como artista y a su trabajo como arte a partir de la validación del crítico, en los nuevos formatos de edición y circulación de la obra. Estas reglas del arte se conjugan con los códigos del mundo digital, suscitando nuevos modos de hacer historietas, mayor interacción entre el historietista y un público fragmentario y nomádico, una legitimación (artística y mercantil) asociada a la «popularidad» de los weblogs... Pero, principalmente, este entramado de sistemas genera desconcierto: en los viejos lectores, que rivalizan con las historietas menos accesibles estética y conceptualmente; en los editores, que van descubriendo cómo publicar y promocionar las historietas; en los productores, que van aprendiendo nuevas formas de difundir y vender su trabajo... El momento actual es clave para definir nuevas reglas en el campo de la historieta y poder articular estas condiciones para impulsar el mercado.

\section{Referencias bibliográficas}

Berone, L. (2009): «La segunda época de la revista Fierro. Notas para un análisis», Tebeosfera, España. Recuperado: 8 de febrero 2012, de $<$ http://www.tebeosfera.com/documentos/documentos/la_segunda_epoca_ de_la_revista_fierro_notas_para_un_analisis_html $>$

Bourdieu, P. (1988): La distinción. $\bar{C}$ riterios y bases sociales del gusto, Madrid, Taurus.

- (1995): Las Reglas del Arte. Génesis y estructura del campo literario, Barcelona, Anagrama.

- (2007): El sentido práctico, Buenos Aires, Siglo Veintiuno Editores.

Caraballo, L. (2010): «Historieta argentina: del fanzine al Weblog», artículo presentado en el Segundo Congreso Iberoamericano de Investigación Artística y Proyectual, Facultad de Bellas Artes, Universidad de La Plata (abril de 2010).

Chartier, R. (2002): El mundo como representación, Barcelona, Gedisa.

ETERNA CADENCIA (2011): «Historieta y novela gráfica /1», panel de historietas y novela gráfica desgrabado y publicado en el blog Eterna Cadencia. Recuperado 27 abril 2012, de 
http://blog.eternacadencia.com.ar/archives/2011/12633

IgARzA, R. (2008): Nuevos medios. Estrategias de convergencia 3.0., Buenos Aires, La Crujía Ediciones.

Martín-Barbero, J. (1987): De los medios a las mediaciones: Comunicación, cultura y hegemonía, Barcelona, Editorial Gustavo Gili.

Mata, M. C. (1997): Públicos y consumos culturales en Córdoba, Córdoba (Argentina), Centro de Estudios Avanzados, Universidad Nacional de Córdoba.

Morley, D. (1996): Televisión, audiencias y estudios culturales, Buenos Aires, Amorrortu.

RegGiani, F. (2009): «Quisiera ser literatura: el prólogo como recurso de legitimación en la edición de libros de historieta en Argentina. El caso de la Biblioteca Clarín de la Historieta», ponencia presentada en VII Congreso Internacional Orbis Tertius de Teoría y Crítica Literaria, Facultad de Humanidades y Ciencias de la Educación, Universidad Nacional de La Plata (18 al 20 de mayo de 2009).

- (2010): «Forma de libro, certificado de obediencia», artículo publicado en blog Hablando del Asunto. Recuperado 1 mayo 2012, de http://hablandodelasunto.com.ar/?p=7219

- (2011): "Cuando la historieta es versión de lo literario», artículo publicado en blog Hablando del Asunto. Recuperado 2 mayo 2012, de http://hablandodelasunto.com.ar/?p=9232

Reguillo, R. (2000): Estrategias del desencanto. Emergencia de culturas juveniles, Buenos Aires, Editorial Norma.

Valenzuela, A. (2009): "Quince de corrido», nota publicada en blog Cuadritos, periodismo de historieta, Argentina (17 de mayo de 2009). Recuperado 22 abril 2012, de

http://avcomics.wordpress.com/2009/05/17/quince-de-corrido/

- (2010): «Max Aguirre y el cierre de su ciclo en Historietas Reales», nota publicada en blog Cuadritos, periodismo de historieta, Argentina (16 de mayo de 2012). Recuperado 2 mayo 2012, de

http://avcomics.wordpress.com/2010/05/16/4638/

- (2011): «Diego Cortés, llevar las historias al límite», publicado en blog Cuadritos, periodismo de historieta, Argentina (30 de enero de 2011). Recuperado 2 mayo 2012, de http://avcomics.wordpress.com/2011/01/30/6981/

VAzQuez, L. (2010): El Oficio de las Viñetas: la industria de la historieta argentina, Buenos Aires, Paidós.

VAzQuez, L. (2011): «De la aventura al evento: Sobre festivales, muestras y rituales», Fierro. La Historieta Argentina, 56: 1-12. 
Verón, E. (1993): La Semiosis Social. Fragmentos de una teoría de la discursividad, Barcelona, Gedisa Editorial.

Von Sprecher, R. (1996): Arte desde los géneros y medios de comunicación masivos en Argentina: modelos de sociedad y de agentes sociales en El Eternauta y en Mort Cinder de Héctor Germán Oesterheld, Informe de Investigación para el Fondo Nacional de las Artes, Córdoba (Argentina), Mimeo.

- (2006): Recepción y consumo de medios masivos de comunicación y de nuevas tecnologías de la información y la comunicación, en la ciudad de La Rioja (República Argentina), Tenerife, Universidad de La Laguna.

Von Sprecher, R.; Williams, J. (2008): «Campo y lenguaje de la historieta argentina: la revista Comiqueando y la trayectoria del campo en los noventa», Estudios y Crítica de la Historieta Argentina, Córdoba. Recuperado 2 mayo 2012, de:

http://historietasargentinas.wordpress.com/2008/11/25/18-campo-y-lenguaje-de-la-historieta-argentina-la-revista-comiqueando-y-la-trayectoria-delcampo-en-los-noventa-roberto-von-sprecher-y-jeff-williams/ 